\title{
Strategies for Good Retention Rates in HIV Exposed Sero-Negatives (HESN) Individuals: Important Consideration for HIV Biomedical Prevention Trials in Nigeria
}

\author{
Evaezi Okpokoro ${ }^{1 *}$, Sophia Osawe ${ }^{1,2}$, Stephen Umaru ${ }^{2}$, Lincoln Egbo ${ }^{2}$, Felicia Okolo1, \\ Pam Datong², Alash'le Abimiku',2,3 \\ ${ }^{1}$ Institute of Human Virology, Abuja, Nigeria \\ ${ }^{2}$ Plateau State Human Virology Research Centre, Jos, Nigeria \\ ${ }^{3}$ Institute of Human Virology, School of Medicine, University of Maryland, Baltimore, USA \\ Email: *eokpokoro@ihvnigeria.org
}

How to cite this paper: Okpokoro, E., Osawe, S., Umaru, S., Egbo, L., Okolo, F., Datong, P. and Abimiku, A. (2018) Strategies for Good Retention Rates in HIV Exposed Sero-Negatives (HESN) Individuals: Important Consideration for HIV Biomedical Prevention Trials in Nigeria. World Journal of AIDS, 8, 160-176.

https://doi.org/10.4236/wja.2018.84012

Received: May 8, 2018

Accepted: December 23, 2018

Published: December 26, 2018

Copyright (ㅇ 2018 by authors and Scientific Research Publishing Inc. This work is licensed under the Creative Commons Attribution-NonCommercial International License (CC BY-NC 4.0). http://creativecommons.org/licenses/by-nc/4.0/ (c) (i) (8) Open Access

\begin{abstract}
Background: Retention in clinical trials is critical for the accumulation of data over time and retaining enough power for comprehensive analysis. We document for the first time the retention rates and factors associated with retention among a cohort of HIV exposed seronegative (HESN) person in a discordant relationship. Understanding these factors will provide valuable cues for maintaining high retention rates in future HIV biomedical prevention studies in this cohort. Aim: We aimed to document retention rates and associated factors relevant in conducting future HIV prevention studies using a cohort of HIV exposed sero-negative individuals. Method: We conducted a prospective cohort study to enroll HESN persons in discordant relationship based on established inclusion criteria that includes: Established serodiscordance with at least 3 months in the relationship; above 18 years and willingness to be followed up. Relevant ethical approvals were obtained. Following informed consent at enrollment, standardized questionnaires on risk behavior and factors that may affect retention were administered at enrollment and during the 2 years follow-up. This was spread over 10 follow-up visits to mimic phase a $2 \mathrm{~b}$ HIV vaccine clinical trial follow up and duration. In addition, clinical examinations were done and samples collected for safety lab during the follow up visits. Estimation of $\mathrm{CD} 4$ and viral load was also done for the HIV+ partners of HESN study participants. Results: Six hundred and sixty HESN persons were screened and 534 (81\%) enrolled (i.e. month 0) and followed up. There was a decline in retention from $96 \%$ at month 1 (visit 1) to $78 \%$ at month 24 (Visit 10). Sharpest drop out from the
\end{abstract}


study occurred at month $1(20 \%)$ and month 15 (14\%) follow-up visits. Inability to reach study participants, unwillingness of study participants to continue study, and mortality of the HIV+ partners of HESN participants were the commonest reasons for participant study termination. Furthermore, no or low level of formal education, (AOR 2.79; 95\% CI 1.29 - 6.02, p = 0.06), being unemployed (AOR 1.96; 95\% CI 1.18 - 3.29, p < 0.01) and inconsistent use of condoms (AOR 1.83; 95\% CI 1.16 - 2.91, p < 0.01) were predictors of non-completion of the study. Conclusion: Retention rates decline especially during month 1 (visit 1) and month 15 (visit 7) mainly due to participants' inability to locate study participants and death of HIV+ partners of HESN enrollees. One unexpected finding from our study is that those who were more consistent in their use of condom were more likely to stay in the study. This is a possible indication of commitment or an incentive for giving free condoms at study visits. This is encouraging for combined biomedical prevention strategies where consistent condoms use is desired. On the other hand, factors such as unemployment, poor formal education and never/occasional condom use were predictors of study drop out. Retention strategies should consider these barriers and predictors of drop out as exclusion criteria in preparation for future HIV biomedical prevention trial.

\section{Keywords}

Retention, HIV Exposed Sero-Negative, Prevention Studies, Clinical Trials

\section{Background}

The HIV epidemic has continued to pose a public health challenge globally. Sub-Saharan Africa (SSA) still carries the burden of the epidemic and accounts for about $70 \%$ of people living HIV/AIDS globally [1]. Nigeria has the second largest epidemic on the African continent, with an estimated 3.2 million adults and children living with HIV/AIDS (1). HIV heterosexual transmission has continued to be a major route of new infections in Nigeria and elsewhere [2]. Heterosexual sero-discordancy, complicated by poor disclosure and low level of condom use among couples, continues to be preventable source of new HIV infections [3] [4] [5] [6]. Consequently, among Zambian and Rwandan heterosexual sero-discordant couples approximately 55.1\% - 92.7\% new HIV infections were reported [7]. In stemming this route of new transmission, HIV sero-discordant couples have provided invaluable data for HIV prevention preparedness studies, demonstrating higher retention rates than other cohorts (USAID HIV prevention for Sero-discordant couples technical brief 2010) [8] and therefore suitable for HIV biomedical prevention trials.

Several factors directly influence participation and retention in HIV biomedical prevention trials. Such factors are usually socioeconomic or cultural in nature and include educational levels, burden of sexually transmitted diseases, poverty, gender inequality, fear of disclosure of HIV status to a partner, long waiting 
hours at a research site [9], stigma [10] [11], transportation costs [12] [13] home-clinic distance [14], and clinical condition of the HIV positive partner [15] [16].

Retention in clinical trials is critical for the accumulation of data over time and retaining enough power for comprehensive analysis. This will ensure that enrollment efforts are not wasted. In preparation for future HIV biomedical prevention trials among HESN partners in Nigeria, we document for the first time the retention rates and factors associated with retention among a cohort of HIV exposed seronegative (HESN) person in a discordant relationship. Understanding these factors will provide valuable cues for maintaining high retention rates in future HIV biomedical prevention studies in this cohort.

\section{Methods}

\subsection{Ethical Statement}

The study was approved by the Plateau State Specialist Hospital Ethics; the National Health Research Ethics and the University of Maryland, School of Medicine Ethics Committees. All study volunteers gave written informed consent before enrollment into the study. The study was conducted following the submission/approval of study protocol and research ethics training for the study team on good clinical and laboratory practice (GCLP).

\subsection{Enrollment and Follow up Visits}

We conducted a 2 years prospective longitudinal study to enroll 500 study HESN participants who routinely visit the counseling unit at Plateau State Human Virology Research Center, (PLASVIREC) in Jos. Plasvirec is located in the premises of Plateau State Specialist Hospital and was established in 2004. Plasvirec is a research and diagnostic center that is ISO 15189 certified. We also recruited from 4 satellite sitesnamely: Church Of Christ In Nigeria (COCIN), Mangu; Abubakar Balewa University Teaching Hospital (ABUTH), Bauchi; Dalhatu Araf Specialist Hospital (DASH), Lafia and Federal Medical Center, Keffi (FMCK). We enrolled eligible study participants based on defined eligibility criteria, such as: being HIV seronegative and in an established sero-discordant relationship for at least 3 months; 18 years and above; ability to provide informed consent; provide locator information and willingness to be followed up; not being pregnant at enrollment if female. Different recruitment strategies were used as reported in our earlier published findings [17].

We enrolled from October 2011 till December 2012 and followed up for 24 months (i.e. the last follow up visit was in December 2014). We administered informed consent enrollment (i.e. visit 1); standardized questionnaires on risk behavior (appendix 1) at enrollment and during the 10 follow up visits and a study termination form to document the reasons for termination (appendix 2). In addition, we performed general clinical examination; obtained samples for safety laboratory tests (i.e. CBC, KFT, LFT, Syphilis, Hep C) and storage during 
each visit. We also performed CD4 and viral load test for HIV+ partners of the HESN who came to the study site during study visits for couple counseling and to support their HESN study volunteers.

\subsection{Retention Strategies}

Once enrolled, the counselors documents the next appointment dates on a detailed study card, hands it over to participants before entering the appointment dates into an electronic diary. Prior to the every next appointment, the data management team generates a list of study participants expected for next appointments using the electronic diary and shares with the counselors. Immediately after every study visit, the data team generates another list of those who missed their appointments (i.e. follow up visits) and shares these with the counselors and tracking team (Figure 1: Study Process and Retention Strategies). The counselors send phone messages to the appointees as a reminder while the tracker makes a voice call or sends a phone message to the enrollee to return to the clinic. In total, five attempts including a home visit were made to encourage the study participants to return to the study. We defined any enrollee as a "defaulter" if they verbally refuse to return to the study. Lost to follow up was used to define enrollees that could not be reached after the phone call or home visits over 3 consecutive follow up visits. We also terminated study participants when they become ineligible following: HIV sero-conversion, pregnancy, separation or divorce, loss to follow up (unable to locate/reach), unwillingness to continue study, migrated from study area, death of HIV+ partner and withdrawal of informed consent.

\subsection{Data Analysis}

We captured participant data using teleform designed case report forms and verified the data using the teleform scanner. Verified data were immediately exported to a Microsoft access database. We performed data cleaning and validation before exporting to STATA (statistical software) for data analysis. We performed descriptive statistics as appropriate (i.e. mean, standard deviation, range, frequencies, and proportion) at baseline for exposure variables of interest (i.e. age, gender, level of education, marital status, religion, employment, enrollment sites, condom use and number of sexual partners) and stratified these according to our outcome variable i.e. whether a participant completed the study or did not. We performed a Chi sq test for dichotomous predictor variable (univariate analysis) and an independent t-test for continuous predictor variable. We also performed a multiple logistic regression modeling based on whether a participant completes the study or did not. We used females, tertiary education, being employed and always using condom as reference values during the multivariate analysis among those terminated from the study. Exposure variables with significance levels of $\mathrm{P} \leq 0.05$ were considered for entry in the regression model. Age and gender were included in the model irrespective of their p-value. Odd ratios with $95 \%$ CI were calculated. Also retention time in study was an outcome variable 


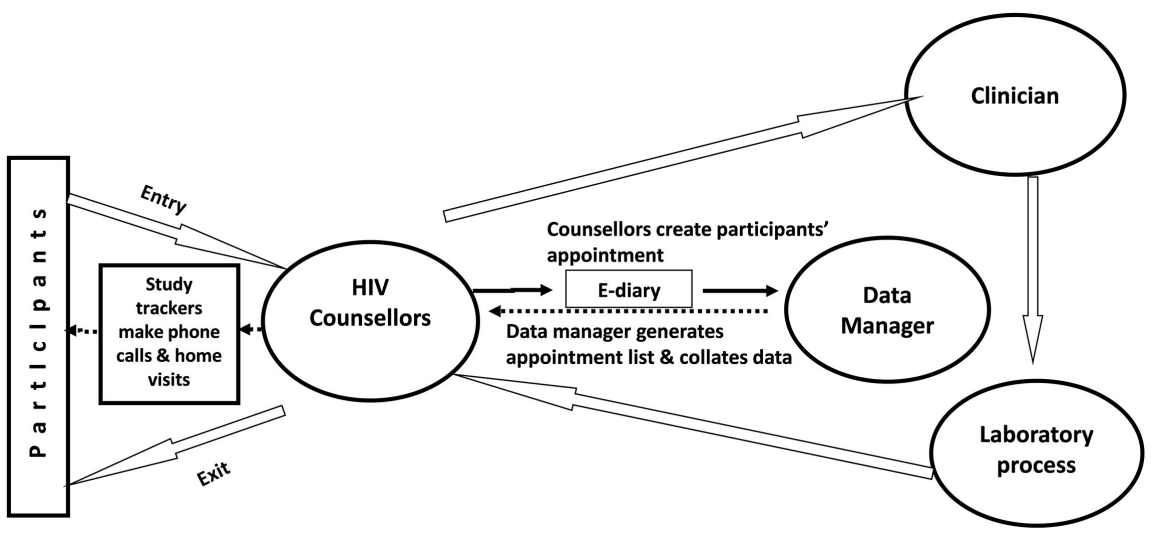

Figure 1. Study process and retention strategies.

and was measured from date of enrollment till date of last study visit (i.e. when follow up visit was interrupted) and analyzed in years.

\section{Results}

A total of 660 HESN partners in a HIV discordant relationship were screened and 540 (82\%) HESN were enrolled based on defined eligibility. Among these 6 HESN were later found to be ineligible as they were confirmed HIV+ during baseline laboratory assessment (i.e. month 0 ) and were terminated from the study. Consequently, 534 (81\%) HESN were eligible for follow-up activities. HIV incidence among $534 \mathrm{HESN}$ was 0.35 per 100 person-years (PY) while the average duration in study was $1.6 \pm 0.6$ years. Of the 534 enrolled HESN, 115 did not complete their visits during the 867.1 person-years follow up visits for several reasons giving a rate of incomplete follow up visit of 13.3 per $100 \mathrm{PY}$.

Demographically, the mean age of the 419 enrollees who completed the study did not differ statistically from the 115 enrollees that did not complete the study (i.e. $38 \pm 9$ vs $36 \pm 9 ; \mathrm{p}=0.07)$. Fifty-three percent (223/419) who completed the study were males compared to $48 \%(55 / 115)$ who did not. Interestingly, $9 \%$ (38/419) of those who completed the study compared to $18 \%$ (21/115) of those who did not had no formal education $(\mathrm{p}<0.01)$. Similarly, only $48 \%(203 / 419)$ of those who completed the study were unemployed compared to $68 \%(78 / 115)$ among those who did not complete the study ( $\mathrm{p}$ value $<0.01$ ). Stratified by study sites, between $13 \%$ (11/81 i.e. in ATBUTH, Bauchi) and 24\% (19/72 in COCIN Mangu) of enrollees did not complete the study. Also, occasional or never use of condom was commoner among those who did not complete the study (i.e. 69\% [79/115] vs 58\% [241/419] $\mathrm{p}=0.03$ ). In addition to the above, other potential determinants of retention at baseline is listed in Table 1.

As expected, retention rates declined gradually from $96 \%$ at month 1 (visit 1 or first FU visit) to $78 \%$ at month 24 (visit 10 or tenth $\mathrm{FU}$ visit)as depicted in Figure 2. The sharpest decline occurred mainly during month 1 (visit 1) and month 15 (visit 7) with $20 \%$ and $14 \%$ of HESN participants not completing their study visits respectively (Figure 3: Termination over Ten study visits over 2 years). 
Among the several reasons for not completing the study, the commonest reasons were: inability to reach or locate participants when they missed study appointments $(23 \%$ [26/115]); participants' inability to come for follow up visits (23\% [26/115]) despite reminders; and mortality of the HIV+ partner $(20 \%$ [23/115]) (Table 2). In a multiple logistic regression to determine predictors of attrition/termination from study; having no education increased the odds of being terminated by about 179\% i.e. 3 folds (AOR 2.79, 95\% CI 1.29 - 6.02), unemployment increased the odds of being terminated by $96 \%$ (AOR 1.96; 95\% CI $1.18-3.29, \mathrm{p}<0.01)$ and inconsistent use of condom increased the odds of being terminated by $83 \%$ (AOR 1.83; 95\% CI 1.16 - 2.91, p > 0.01). These predictors remained statistically significant even after controlling for possible confounders (Table 3).

Table 1. Baseline socio demographic and risk among study participants.

\begin{tabular}{|c|c|c|c|c|c|}
\hline Characteristics & & $\begin{array}{l}\text { Completed the study } \\
\text { visits } \mathrm{N}=419(\%)\end{array}$ & $\begin{array}{c}\text { Not complete the } \\
\text { study visits } \\
\mathrm{N}=115(\%)\end{array}$ & $\begin{array}{l}\text { Total Study } \\
\text { Participants } \\
\mathrm{N}=534(\%)\end{array}$ & $\begin{array}{l}\text { Univariate } \\
\text { Analysis } \\
\text { p-value }\end{array}$ \\
\hline \multirow[t]{2}{*}{ Age (years) } & Mean \pm SD & $38 \pm 9$ & $36 \pm 9$ & $37 \pm 9$ & $0.07^{\#}$ \\
\hline & Range & $20-65$ & $19-63$ & $19-65$ & \\
\hline \multirow[t]{4}{*}{ Age group } & $20-30$ & $103(25)$ & $33(29)$ & $136(26)$ & $0.22^{*}$ \\
\hline & $31-40$ & $182(43)$ & $55(48)$ & $236(44)$ & \\
\hline & $41-50$ & $100(24)$ & $17(15)$ & $118(22)$ & \\
\hline & $>50$ & $34(8)$ & $10(9)$ & $44(8)$ & \\
\hline \multirow[t]{2}{*}{ Gender } & Male & $223(53)$ & $55(48)$ & $278(52)$ & 0.31 \\
\hline & Female & $196(47)$ & $60(52)$ & $256(48)$ & \\
\hline \multirow[t]{4}{*}{ Education } & None & $38(9)$ & $21(18)$ & $59(11)$ & $0.00^{*}$ \\
\hline & Primary & $105(25)$ & $32(28)$ & $137(26)$ & \\
\hline & Secondary & $122(29)$ & $38(33)$ & $160(30)$ & \\
\hline & Tertiary & $154(37)$ & $24(21)$ & $178(33)$ & \\
\hline \multirow[t]{2}{*}{ Marital Status } & Married & $416(99)$ & $113(98)$ & $529(99)$ & 0.52 \\
\hline & In a relationship or cohabiting & $3(1)$ & $2(2)$ & $5(1)$ & \\
\hline \multirow[t]{2}{*}{ Religion } & Christianity & $323(77)$ & $85(74)$ & $408(76)$ & 0.47 \\
\hline & Muslim & $96(23)$ & $30(26)$ & $126(24)$ & \\
\hline Employed & Yes & $216(52)$ & $37(32)$ & $253(47)$ & \\
\hline \multirow[t]{5}{*}{ Enrollment site } & PLASVIREC Jos & $156(37)$ & $47(41)$ & $205(38.4)$ & $0.33^{*}$ \\
\hline & COCIN Mangu & $54(13)$ & $19(17)$ & $72(13.5)$ & \\
\hline & ATBUTH Bauchi & $72(17)$ & $11(10)$ & $81(15.2)$ & \\
\hline & FMC-Keffi & $30(7)$ & $9(8)$ & $39(7.3)$ & \\
\hline & DASH Lafia & $107(26)$ & $29(25)$ & $137(25.6)$ & \\
\hline \multirow[t]{2}{*}{ Condom use } & Always & $178(42)$ & $36(31)$ & $214(40)$ & 0.03 \\
\hline & Occasionally or Never & $241(58)$ & $79(69)$ & $320(60)$ & \\
\hline \multirow[t]{2}{*}{ No of Sex partners } & $<2$ & $389(93)$ & $103(90)$ & $492(92)$ & 0.25 \\
\hline & $\geq 2$ & $30(7)$ & $12(10)$ & $42(8)$ & \\
\hline
\end{tabular}

\#Students T-test was done, ${ }^{*}$ Likelihood Ratio Test Chi-sq was used. 
Table 2. Reasons given for Incomplete Follow up visit.

\begin{tabular}{|c|c|c|c|c|c|c|c|c|c|c|c|}
\hline Reason for termination from study & $\begin{array}{l}{ }^{*} \text { FUV } \\
{ }^{\mathrm{g}} \mathrm{M} 1\end{array}$ & $\begin{array}{l}\text { 2FUV } \\
\text { M2 }\end{array}$ & $\begin{array}{l}\text { 3FUV } \\
\text { M3 }\end{array}$ & $\begin{array}{l}\text { 4FUV } \\
\text { M6 }\end{array}$ & $\begin{array}{l}\text { 5FUV } \\
\text { M9 }\end{array}$ & $\begin{array}{l}\text { 6FUV } \\
\text { M12 }\end{array}$ & $\begin{array}{l}\text { 7FUV } \\
\text { M15 }\end{array}$ & $\begin{array}{l}\text { 8FUV } \\
\text { M18 }\end{array}$ & $\begin{array}{l}\text { 9FUV } \\
\text { M21 }\end{array}$ & $\begin{array}{l}\text { 10FUV } \\
\text { M24 }\end{array}$ & $\begin{array}{c}\mathrm{N} \\
(\%)\end{array}$ \\
\hline$\frac{\text { Death of HESN }}{\text { study participant }}$ & 0 & 0 & 0 & 2 & 1 & 1 & 0 & 1 & 0 & 0 & $\begin{array}{c}5 \\
(4.4)\end{array}$ \\
\hline$\frac{\text { Migrated from }}{\text { study area }}$ & 3 & 0 & 0 & 1 & 1 & 1 & 0 & 0 & 0 & 0 & $\begin{array}{c}6 \\
(5.2)\end{array}$ \\
\hline$\frac{\text { HESN }}{\text { seroconverted }}$ & 0 & 1 & 0 & 0 & 2 & 0 & 0 & 0 & 0 & 0 & $\begin{array}{c}3 \\
(2.6)\end{array}$ \\
\hline$\frac{\text { Unable to reach }}{\text { or locate (attrition) }}$ & 1 & 0 & 2 & 2 & 5 & 5 & 9 & 2 & 0 & 0 & $\begin{array}{c}26 \\
(22.6)\end{array}$ \\
\hline$\frac{\text { Separate/Divorce from HIV + partner }}{\underline{\text { (thus ineligible to remain in study) }}}$ & 2 & 3 & 1 & 1 & 1 & 2 & 1 & 2 & 4 & 0 & $\begin{array}{c}17 \\
(14.8)\end{array}$ \\
\hline $\begin{array}{l}\text { Death of HIV+ partner } \\
\text { (thus ineligible to remain in the study) }\end{array}$ & 0 & 3 & 3 & 5 & 3 & 3 & 3 & 3 & 0 & 0 & $\begin{array}{c}23 \\
(20)\end{array}$ \\
\hline $\begin{array}{c}\text { Unwilling to } \\
\text { continue study }\end{array}$ & 15 & 1 & 1 & 2 & 1 & 2 & 2 & 0 & 1 & 1 & $\begin{array}{c}26 \\
(22.6)\end{array}$ \\
\hline $\begin{array}{l}\stackrel{\text { Pregnancy }}{\text { (thus ineligible to remain in study) }} \\
\underline{\underline{y}}\end{array}$ & 1 & 0 & 2 & 1 & 0 & 0 & 1 & 0 & 0 & 1 & $\begin{array}{c}6 \\
(5.2)\end{array}$ \\
\hline$\frac{\text { Participant }}{\text { withdrew consent }}$ & 0 & 1 & 0 & 0 & 0 & 0 & 0 & 2 & 0 & 0 & $\begin{array}{c}3 \\
(2.6)\end{array}$ \\
\hline $\begin{array}{c}\text { Total N } \\
(\%)\end{array}$ & $22(19)$ & $\begin{array}{c}9 \\
(8)\end{array}$ & $\begin{array}{c}9 \\
(8)\end{array}$ & $\begin{array}{c}14 \\
(12)\end{array}$ & $\begin{array}{c}14 \\
(12)\end{array}$ & $\begin{array}{c}14 \\
(12)\end{array}$ & $\begin{array}{c}16 \\
(14)\end{array}$ & $\begin{array}{l}10 \\
(9)\end{array}$ & $\begin{array}{c}5 \\
(4.3)\end{array}$ & $\begin{array}{c}2 \\
(1.7)\end{array}$ & $\begin{array}{c}115 \\
(100)\end{array}$ \\
\hline
\end{tabular}

${ }^{*} \mathrm{FUV}=$ Follow up visit, ${ }^{5} \mathrm{M}=$ Month.

Table 3. Multivariate logistic regression of predictors of study termination.

\begin{tabular}{|c|c|c|c|c|c|c|c|}
\hline \multicolumn{8}{|c|}{ Terminated (Yes or No) } \\
\hline Variable & & $\begin{array}{l}\text { Terminated from } \\
\text { study }\end{array}$ & $\mathrm{OR}^{\mathrm{ua}}$ & $95 \% \mathrm{CI}$ & AOR & $95 \% \mathrm{CI}$ & $P$-value \\
\hline Age & & $36 \pm 9$ & 0.97 & $0.96-1.0$ & 0.98 & $0.96-1.0$ & 0.20 \\
\hline \multirow[t]{2}{*}{ Sex } & Male & $55(48)$ & 0.81 & $0.53-1.20$ & 1.3 & $0.79-2.12$ & 0.30 \\
\hline & Female & $60(52)$ & Ref & & Ref & & \\
\hline \multirow[t]{4}{*}{ Education } & None & $21(18)$ & 3.54 & $1.78-7.03$ & 2.79 & $1.29-6.02$ & $0.06^{\star}$ \\
\hline & Primary & $32(28)$ & 1.95 & $1.09-3.50$ & 1.64 & $0.86-3.11$ & \\
\hline & Secondary & $38(33)$ & 1.99 & $1.13-3.51$ & 1.78 & $0.98-3.23$ & \\
\hline & Tertiary & $24(21)$ & Ref & & Ref & & \\
\hline \multirow[t]{2}{*}{ Employed } & Yes & $37(32)$ & Ref & & Ref & & \\
\hline & No & $78(68)$ & 2.25 & $1.46-3.49$ & 1.96 & $1.18-3.49$ & 0.01 \\
\hline \multirow[t]{2}{*}{ Condom use } & Always & $36(31)$ & Ref & & Ref & & \\
\hline & Occasionally or Never & $79(69)$ & 1.62 & $1.04-2.51$ & 1.83 & $1.16-2.91$ & 0.01 \\
\hline
\end{tabular}

ua Unadjusted Odd Ratio, ${ }^{\text {AOR }}$ Adjusted Odd Ratio after inclusion of age, sex, education, employed and condom use in the model, ${ }^{*}$ Likelihood Ratio Test Chi-sq was used. 


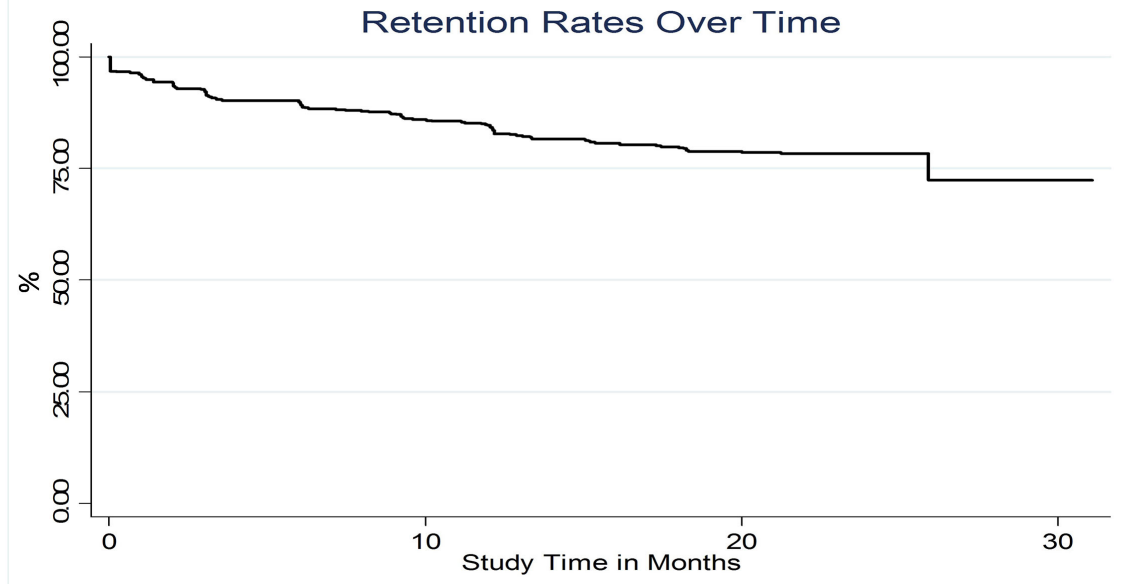

Figure 2. Retention of study participants over ten study visits spread over 2 years.

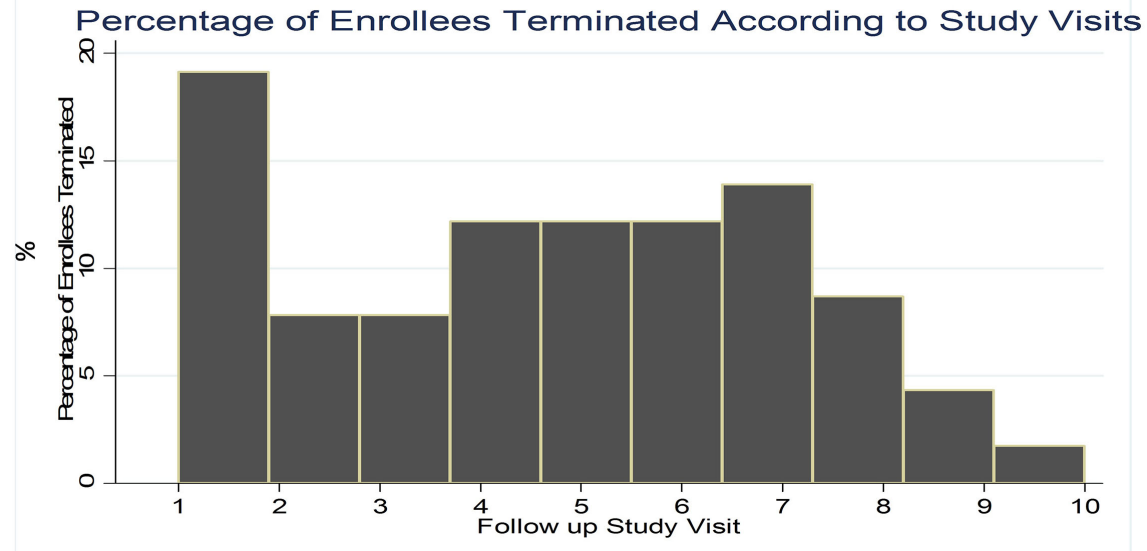

Figure 3. Termination over ten study visits over 2 years.

\section{Discussion}

In this longitudinal cohort study involving HESN partners in a sero-discordant relationship in Nigeria, we found that retention rates gradually declined over time to $78 \%$ at the end of a 2-year follow up (Figure 2: Retention of Study Participants over Ten study visits spread over 2 years) which is below the arbitrary $90 \%$ retention benchmark target for the study. Nonetheless, lower retention rates of $62 \%$ to $88 \%$ have been reported in other longitudinal studies [18] [19] [20] which makes the retention rate of $78 \%$ for this study encouraging for a study site just embarking on preparations for biomedical prevention studies. A significant factor for the drop in retention rate is death of HIV+ partner and separation/divorce so that if one considers the retention rate without these 2 factors; then it is closer to the benchmark at $86 \%$.

Among predictors associated with lower retention rates, we found indicators of low socio-economic status (i.e. no formal education and unemployment) as significant culprits. We suspect study participants with no formal education 
might be quick to join the study but may not have fully understood the risks and benefits of the study despite the rigorous process of consenting prior to enrollment and only understood following repeated consenting at each study visits and decided not to participate. Comparable findings were reported in a multi-centre IDEFICS (identification and prevention of dietary- and lifestyle-induced health effects in children and infants) which associated low parental education with attrition [21]. While it is suggestive that unemployment should provide more time for participants to keep up with study clinic appointments, we found the revise in our study, which could be due to financial constrains for the unemployed. Thus strategies to ensure retention of trial participants from low SES should be enhanced as this would lead to more generalizable findings [22].

Though sparsely documented in other studies, we found that risk reduction behavior such frequency of condom use also predicted retention among HESN. Participants who never or occasionally use condom had lower odds of being retained due to incomplete follow up visits. This could again point to the general level of commitment of the participants to sustain an activity or that the provision of free condoms at each visit may have inevitably become an incentive for these study participants that consistently use condoms to complete their follow up visits. A study conducted among a cohort of MSM in China, also reported higher retention among study participants who received condoms and lubricants [23].

As shown and categorized in Table 2, several individual reasons were identified for the drop in retention rate over the 2 years follow up. For instance, majority of participants were unwilling to continue the study after enrolment despite repeated reminders and home visits by the study tracker. This may be as a result of competing socioeconomic commitments considering that majority of Nigerians live below the poverty line [24] or may be due to other individual barriers [25] such as lack of interest in the study after having had enough time to think about it or due to influence from peers or family members outside the study. Furthermore, the security crisis due to the Boko Haram attacks and civil unrest affected participants' ability to continue with their follow up visits for fear of terror attacks. Another major reason for the drop in retention is that a number of participants, who missed their schedule appointments, could not be reached at the physical address they provided during enrollment. Nigerians are generally sceptical about giving out their addresses considering the ongoing security challenges in Nigeria. Some participants also became internally displaced persons following terror attacks, thus relocating from the initial address given during enrollment without notifying the study trackers. Other studies involving families from low socioeconomic and ethnic minority background have also cited poor notification of changed address as reasons for low retention rates as well [22].

As noted earlier, factors affecting the HIV+ partners of the study enrollees such as mortality and separation/divorce rendered the HIV negative partner in- 
eligible for study follow up visits as the couple is expected to be in sero-discordant relationship during the course of the study. As a result, the 23 deaths of HIV+ partner despite being on ART plus 17 separation/divorce significantly reduced the retention rates of the study. There were a total of five deaths among the HESN participants: 2 from hypertensive related causes, 1 from food poisoning, 1 from road traffic accident and 1 was unknown cause. Predictors associated with these deaths are being detailed in another manuscript (Okpokoro et al. manuscript in-preparation). Considering the link between low CD4 count and high HIV viral load to HIV related mortality [15], it may be important in the future to include low CD4 count and high viral load of HIV+ partnersas exclusion criteria for enrollment of HIV sero-discordant couple into clinical trials in order to improve the retention rates. In our study cohort, $15 \%$ of couples were either separated or divorced compared with $4 \%$ reported by Rwanda Zambia HIV research group [26]. We could not ascertain the reason for this but it may be due to different coping mechanisms or/and support between different cultures to the psychosocial, emotional or reproductive burden associated with HIV infection among sero-discordant couple [26]. Future prevention studies in this population should consider engaging psychologist to support participants cope with these issues.

Biphasic substantial loss of study participants occurred during month 1 (visit 1) and month 15 (visit 7) visits (i.e. 20\% \& 14\% respectively). These losses were lower than the $24.9 \%$ and $30.5 \%$ reported by the Rwanda Zambia HIV group [26] in their HESN cohort. The highest number of participant loss occurred during month 1 follow up visit probably because participants who willingly and excitedly enrolled into the study could not meet up with their commitment due to physical and financial demands [27]. Such demands could include distance from study clinic, transportation mechanism, waiting time before and during administration of study processes [14] [22]. The second bout of decrease in retention occurred during month 15 (visit 7) follow up visit and may be as a result of participants' exhaustion from research related activities over time or Boko Haram activities.

Slightly fewer females (48\% [256/534]) compared to males enrolled for the study. Allen et al. also reported a similar finding that, discordant couples with a female HIV negative partner $\left(\mathrm{F}^{-} \mathrm{M}^{+}\right)$had fewer study enrollees compared to discordant couples with a female HIV positive partner $\left(\mathrm{F}^{+} \mathrm{M}^{-}\right)$[25]. Despite having fewer female enrollees in our study, more females (52\% [60/115]) did not complete the study follow up visits (i.e. visit 1 to 10 ) giving an incidence rate of incomplete follow up of 14.5 per 100 PY against 12.1 per 100 PY among males. This is in contrast to that reported Allen et al. [26] considering the difference in study setting. Our findings may be due to the limited ability of women to make decisions for themselves: the husband may decide to stop his wife from participating when the study is protracted [28]. This is unlike other studies that documented men as more likely not to complete their research follow up visits [14] [29] considering the need to fend for their families. This is an area for a more 
detailed socio behavioral study in the future.

This study had some limitation. We were unable to document family income, transport mechanism, distance home to clinic as we could not validate these. Rather as a surrogate, we obtained educational and employment status. More so, irrespective of transport mechanism and distance to clinic, all study participants were re-imbursed their transportation cost. Boko Haram terrorist activities in the north central and north east part of the country necessitated relocation and unwillingness of some study participants to come for their follow up visits. This also limited the ability of study trackers to routinely track some participants living in volatile suburbs. Nonetheless, our study identifies areas for future research such as newer retention strategies during period of unexpected crisis, the difference between the genders in retention rates, and the provision of condom as an incentive for retention.

\section{Conclusions}

Retention rates decline especially during month 1 (visit 1) and month 15 (visit 7) mainly due to participants' inability to locate study participants and death of HIV+ partners of HESN enrollees. This demonstrates the importance of wellness of the HIV+ partner as indicated by their viral load and CD4 count for participation of their HESN partner in these studies. One unexpected finding from our study is that those who were more consistent in their use of condom were more likely to be stay in the study. This is a possible indication of commitment or an incentive for giving free condoms at study visits. This is encouraging for combined biomedical prevention strategies where consistent condoms use is desired in addition to other prevention strategies.

On the other hand, factors such as unemployment, poor formal education, and never/occasional condom use were predictors of study drop out. Separation/divorce is also another major reason for the termination of participants from the study which underscores the importance of couple testing and psychological support as a possible prerequisite in improving retention. Retention strategies should consider these barriers and predictors of drop out as exclusion criteria in preparation for future HIV biomedical prevention trial.

\section{Acknowledgements}

This work was carried out with support from the Canadian Global Health Research Initiative (GHRI) composed of the Canadian Institute of Health Research, the Canadian International Development Agency and the International Development Research Center. We thank all the enrollees that volunteered to take part in our study and dedicated time to come for their follow up visits. We would also like to acknowledge the following individuals who contributed in various ways towards the success of this study: Grace Choji, Ruth Daitiri, Sam Audu, Othniel Luka, Rahila Pam, Nenbam Daniel, Magdalene Yager, and Late Nuhu. 


\section{Conflicts of Interest}

The authors declare no conflicts of interest regarding the publication of this paper.

\section{References}

[1] UNAIDS Factsheet 2014.

[2] Ikechebelu, J., Mbamara, S.U., Joe-Ikechebebelu, N.N. and Ezenwabachili, A.O. (2009) Sexual Practices of People Living with HIV in South Eastern Nigeria. Nigerian Journal of Clinical Practice, 12, 416-420.

[3] Eyawo, O., de Walque, D., Ford, N., Gakii, G., Lester, R.T. and Mills, E.J. (2010) HIV Status in Discordant Couples in Sub-Saharan Africa: A Systematic Review and Meta-Analysis. The Lancet Infectious Diseases, 10, 770-777. https://doi.org/10.1016/S1473-3099(10)70189-4

[4] Lingappa, J.R., Lambdin, B., Bukusi, E.A., Ngure, K., Kavuma, L., Inambao, M., et al. (2008) Regional Differences in Prevalence of HIV-1 Discordance in Africa and Enrollment of HIV-1 Discordant Couples into an HIV-1 Prevention Trial. PLoS One, 3, e1411. https://doi.org/10.1371/journal.pone.0001411

[5] Robinson, N.J., Mulder, D., Auvert, B., Whitworth, J. and Hayes, R. (1999) Type of Partnership and Heterosexual Spread of HIV Infection in Rural Uganda: Results from Simulation Modelling. International Journal of STD \& AIDS, 10, 718-725. https://doi.org/10.1258/0956462991913394

[6] Carpenter, L.M., Kamali, A., Ruberantwari, A., Malamba, S.S. and Whitworth, J.A. (1999) Rates of HIV-1 Transmission within Marriage in Rural Uganda in Relation to the HIV Sero-Status of the Partners. AIDS, 13, 1083-1089. https://doi.org/10.1097/00002030-199906180-00012

[7] Dunkle, K.L., Stephenson, R., Karita, E., Chomba, E., Kayitenkore, K., Vwalika, C., et al. (2008) New Heterosexually Transmitted HIV Infections in Married or Cohabiting Couples in Urban Zambia and Rwanda: An Analysis of Survey and Clinical Data. Lancet, 371, 2183-2191. https://doi.org/10.1016/S0140-6736(08)60953-8

[8] Curran, K., Baeten, J.M., Coates, T.J., Kurth, A., Mugo, N.R. and Celum, C. (2012) HIV-1 Prevention for HIV-1 Serodiscordant Couples. Current HIV/AIDS Reports, 9, 160-170. https://doi.org/10.1007/s11904-012-0114-Z

[9] Roura, M., Urassa, M., Busza, J., Mbata, D., Wringe, A. and Zaba, B. (2009) Scaling up Stigma? The Effects of Antiretroviral Roll-Out on Stigma and HIV Testing. Early Evidence from Rural Tanzania. Sexually Transmitted Infections, 85, 308-312. https://doi.org/10.1136/sti.2008.033183

[10] Hardon, A.P., Akurut, D., Comoro, C., Ekezie, C., Irunde, H.F., Gerrits, T., et al. (2007) Hunger, Waiting Time and Transport Costs: Time to Confront Challenges to ART Adherence in Africa. AIDS Care, 19, 658-665. https://doi.org/10.1080/09540120701244943

[11] Otieno, P.A., Kohler, P.K., Bosire, R.K., Brown, E.R., Macharia, S.W. and John-Stewart, G.C. (2010) Determinants of Failure to Access Care in Mothers Referred to HIV Treatment Programs in Nairobi, Kenya. AIDS Care, 22, 729-736. https://doi.org/10.1080/09540120903373565

[12] Maskew, M., MacPhail, P., Menezes, C. and Rubel, D. (2007) Lost to Follow Up: Contributing Factors and Challenges in South African Patients on Antiretroviral Therapy. South African Medical Journal, 97, 853-857. 
[13] Ezechi, O.C., Gab-Okafor, C., Onwujekwe, D.I., Adu, R.A., Amadi, E. and Herbertson, E. (2009) Intimate Partner Violence and Correlates in Pregnant HIV Positive Nigerians. Archives of Gynecology and Obstetrics, 280, 745-752. https://doi.org/10.1007/s00404-009-0956-9

[14] Conley, N.J., Pavlinac, P.B., Guthrie, B.L., Mackelprang, R.D., Muiru, A.N., Choi, R.Y., et al. (2012) Distance from Home to Study Clinic and Risk of Follow-Up Interruption in a Cohort of HIV-1-Discordant Couples in Nairobi, Kenya. PLoS One, 7, e43138. https://doi.org/10.1371/journal.pone.0043138

[15] de Bruyn, G., Magaret, A., Baeten, J.M., Lingappa, J.R., Ndase, P., Celum, C., et al. (2012) Mortality in Members of HIV-1 Serodiscordant Couples in Africa and Implications for Antiretroviral Therapy Initiation: Results of Analyses from a Multicenter Randomized Trial. BMC Infectious Diseases, 12, 277. https://doi.org/10.1186/1471-2334-12-277

[16] Hudson, C.P. (1996) The Importance of Transmission of HIV-1 in Discordant Couples in the Population Dynamics of HIV-1 Infection in Rural Africa. International Journal of STD \& AIDS, 7, 302-304.

[17] Osawe, S., Okpokoro, E., Datiri, R., Choji, G., Okolo, F., Datong, P. and Abimiku, A. (2016) Development of a Prospective Cohort of HIV Exposed Sero-Negative (HESN) Individuals in Jos Nigeria. BMC Infectious Diseases, 16, 352. https://doi.org/10.1186/s12879-016-1649-1

[18] Brown-Peterside, P., Chiasson, M.A., Ren, L., et al. (2000) Involving Women in HIV Vaccine Efficacy Trials: Lessons Learned from a Vaccine Preparedness Study in New York City. Journal of Urban Health, 77, 425-437.

[19] Mehendale, S.M., Ghate, M.V., Kishore Kumar, B., Sahay, S., Gamble, T.R., Godbole, S.V., et al. (2006) Low HIV-1 Incidence among Married Serodiscordant Couples in Pune, India.

[20] Seage, G.R., Holte, S.E., Metzger, D., Koblin, B.A., Gross, M., Celum, C., et al. (2001) Are US Populations Appropriate for Trials of Human Immunodeficiency Virus Vaccine? The HIVNET Vaccine Preparedness Study. American Journal of Epidemiology, 153, 619-627. https://doi.org/10.1093/aje/153.7.619

[21] Sabrina, H., Pohlabeln, H., Michels, N., Mårild, S., Lissner, L., Kovacs, E., et al. (2013) Determinants of Attrition to Follow-Up in a Multicentre Cohort Study in Children-Results from the IDEFICS Study. Epidemiology Research International, 2013, Article ID: 936365.

[22] Brannon, E.E., Kuhl, E.S., Boles, R.E., Aylward, B.S., Ratcliff, M.B., Valenzuela, J.M., et al. (2013) Strategies for Recruitment and Retention of Families from Low-Income, Ethnic Minority Backgrounds in a Longitudinal Study of Caregiver Feeding and Child Weight. Child Health Care, 42, 198-213. https://doi.org/10.1080/02739615.2013.816590

[23] Peng, Z., Yang, H., Norris, J., Chen, X., Huan, X., et al. (2012) HIV Incidence and Predictors Associated with Retention in a Cohort of Men Who have Sex with Men in Yangzhou, Jiangsu Province, China. PLoS ONE, 7, e52731. https://doi.org/10.1371/journal.pone.0052731

[24] Index Mundi (2014) Nigeria Population below Poverty Line.

[25] Ejiogu, N., Norbeck, J.H., Mason, M.A., Cromwell, B.C., Zonderman, A.B. and Evans, M.K. (2011) Recruitment and Retention Strategies for Minority or Poor Clinical Research Participants: Lessons from the Healthy Aging in Neighborhoods of Diversity across the Life Span Study. Gerontologist, 51, S33-S45. https://doi.org/10.1093/geront/gnr027 
[26] Mirjam-Colette, K., Allen, S., Zulu, I., Kancheya, N., Stephenson, R., Brill, I., et al. (2008) Enrollment and Retention of HIV Discordant Couples in Lusaka, Zambia. JAIDS Journal of Acquired Immune Deficiency Syndromes, 47, 116-125. https://doi.org/10.1097/QAI.0b013e31815d2f3f

[27] Sullivan, J. (2004) Subject Recruitment and Retention: Barriers to Success. Applied Clinical Trials.

[28] Hargreaves, J.R., JR. G. (2002) Educational Attainment and HIV-1 Infection in Developing Countries: A Systematic Review. Tropical Medicine \& International Health, 7, 489-498. https://doi.org/10.1046/j.1365-3156.2002.00889.x

[29] Ekouevi, D.K., Balestre, E., Ba-Gomis, F.O., Eholie, S.P., Maiga, M., Amani-Bosse, C., et al. (2010) Low Retention of HIV-Infected Patients on Antiretroviral Therapy in 11 Clinical Centres in West Africa. Tropical Medicine \& International Health, 15, 34-42. https://doi.org/10.1111/j.1365-3156.2010.02505.x 


\section{Appendix 1: Risk Behavior Form}

Clisic Date (DD/MM/YYYY):
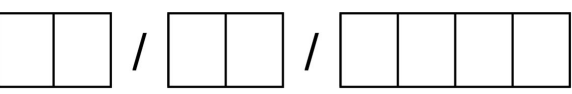

Visit Number

Name of staff completing the form:

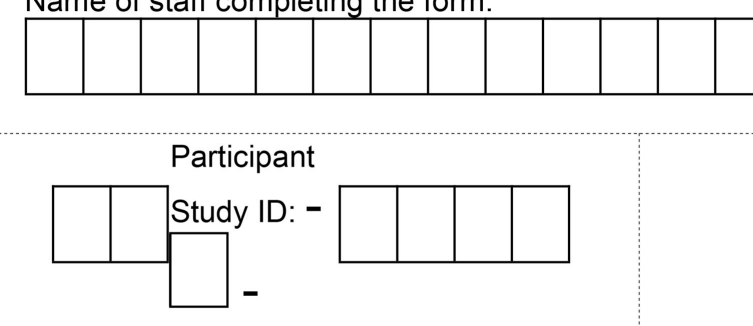

1. How many sex partners have you had in the last
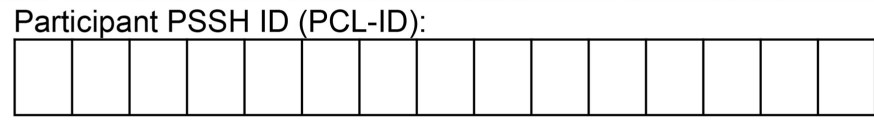

\section{Are your partners:O Male O Female OBoth}

3. How many days in a week do you have

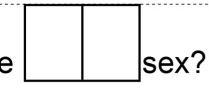
one month?

Refused to answerUnknown

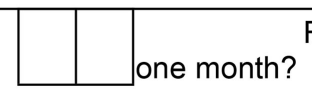

4. Do you participate in the following? $\quad 0 \quad 000$

$\begin{array}{rrrr}\text { Oral } & 0 & 0 \begin{array}{l}\text { sex:YesNoRefused } \\ \text { answerDon't know } \\ \text { sex:YesNoRefused } \\ \text { answerDon't know }\end{array} & \begin{array}{r}\text { to } \\ \text { Vaginal } \\ \text { to }\end{array}\end{array}$

5. Have you ever had the following disease conditions?

O Hepatitis A O Hepatitis BO Hepatitis COSTI None
6. Have you ever had sex with somone
O $\quad 0$ diagnosed with?
(Shade all that apply)
Hepatitis $\mathrm{O}$
BSTI

7. Have you been vaccinated against Hepatitis $B$ ?: O Yes know

8. Have you had blood transfusion in the last one year?: OYes O No O Refused to answer O Don't know

9. Are you involved in intravenous drug use? (e.g. cocaine): OYes $\quad$ ONo O Refused to answer $O$ Don't know

10. When you have sex do you use condom or other barrier?: OAlways OSometimes ONever

$$
\text { If NO, } \quad \mathrm{O} \text { why?Partner refuses to } \mathrm{O} \text { use theml use condom but they break }
$$$$
\text { O I trust my partnerl don't } \mathrm{O} \text { enjoy using condoms }
$$$$
\text { O I do not have anyOther } 0
$$ 


\section{Appendix 2: Study Termination Form}

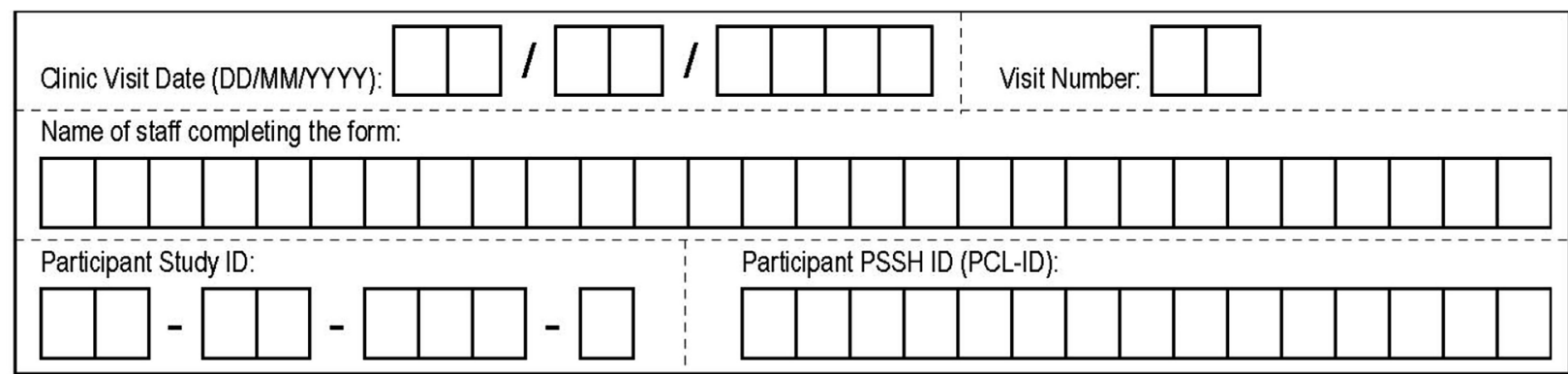

STF1. Date of Termination (DD/MM/YYYY):

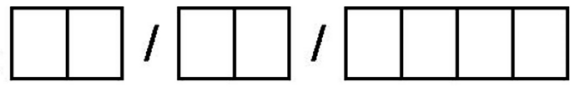

STF2. Date of last known study visit (DD/MM/YYYY)

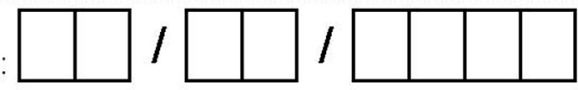

STF3. Primary reason for study termination

O Did not meet eligibility criteria for study follow-up

O Complete follow-up/End of the study

O Migrated from study area

O Unable to reach/ocate participant

O Unable/Unwilling to attend clinic visits

O Participant withdrew consent

O Investigator decided to end study subject's participation O Sero converts

O Significantly derranged lab results

O Adverse event

Death

(If significantly derranged lab results, specify reason):

(If adverse event, specify grade): O Grade $1 \quad$ OGrade $2 \quad$ OGrade $3 \quad$ O Grade 4

Date of Demise (DD/MMMYYY):
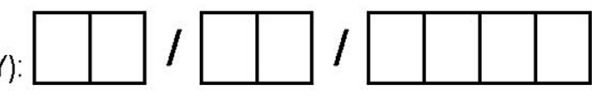

\section{O Unknown}

Did participant die in hospital? $O$ Yes $O$ No $O$ Unknown $O$ Refused to answer

If yes, what is the name of the hospital?

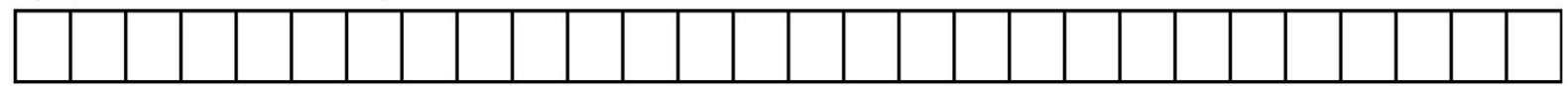

Death was caused by: $\mathbf{O}$ Injury/trauma $\mathbf{O}$ llness $\mathrm{O}$ Unknown $\mathrm{O}$ Refused to answer

(Specify information avaialable about cause of death)

Page 1 of 2 
Source of information regarding the participant's death (Shade only one):

O Family Member (Specify relation to participant below)

O Friend/Neighbour (specify below)

O Other (Specify below)

Specify source of death information:

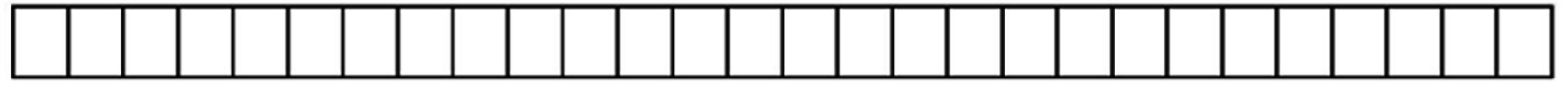

Comments:

Counselor Name:

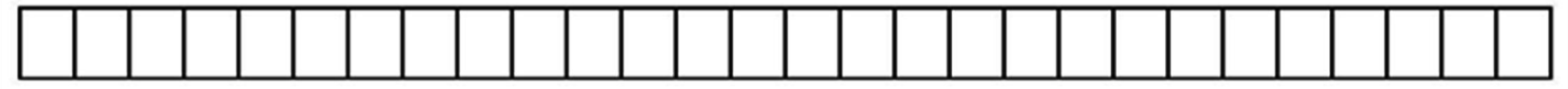

Data entry completed (DD/MMMYYY): \begin{tabular}{|l|l|l|l|l|l|l|}
\hline & & & \\
\hline
\end{tabular} 